\title{
Dietary networks identified by Gaussian graphical model and general and abdominal obesity in adults
}

Ahmad Jayedi ${ }^{1,2}$, Nasim Janbozorgi ${ }^{2}$, Kurosh Djafarian $^{3}$, Mir Saeed Yekaninejad ${ }^{4}$ and Sakineh Shab-Bidar ${ }^{2 *}$

\begin{abstract}
Background: Gaussian graphical model (GGM) has been introduced as a new approach to identify patterns of dietary intake. We aimed to investigate the link between dietary networks derived through GGM and obesity in Iranian adults.
\end{abstract}

Method: A cross-sectional study was conducted on 850 men and women (age range: 20-59years) who attended the local health centers in Tehran. Dietary intake was evaluated by using a validated food frequency questionnaire. GGM was applied to identify dietary networks. The odds ratios (ORs) and 95\% confidence intervals (Cls) of general and abdominal adiposity across tertiles of dietary network scores were estimated using logistic regression analysis controlling for age, sex, physical activity, smoking status, marital status, education, energy intake and menopausal status.

Results: GGM identified three dietary networks, where 30 foods were grouped into six communities. The identified networks were healthy, unhealthy and saturated fats networks, wherein cooked vegetables, processed meat and butter were, respectively, central to the networks. Being in the top tertile of saturated fats network score was associated with a higher likelihood of central obesity by waist-to-hip ratio (OR: 1.56, 95\%Cl: 1.08, 2.25; $P$ for trend: 0.01 ). There was also a marginally significant positive association between higher unhealthy network score and odds of central obesity by waist circumference (OR: 1.37, 95\% Cl: 0.94, 2.37; $P$ for trend: 0.09). Healthy network was not associated with central adiposity. There was no association between dietary network scores and general obesity.

Conclusions: Unhealthy and saturated fat dietary networks were associated with abdominal adiposity in adults. GGM-derived dietary networks represent dietary patterns and can be used to investigate diet-disease associations.

Keywords: Abdominal obesity, Dietary network, Dietary pattern, Diet quality, Obesity

\section{Background}

There was a rising trend in obesity during the past decades globally [1]. Currently, approximately one-third of the world's population is overweight or obese [2]. Adiposity, mainly reflected by increased body mass index (BMI), is linked to a greater risk of cardiometabolic

\footnotetext{
${ }^{*}$ Correspondence: s.shabbidar@gmail.com

${ }^{2}$ Department of Community Nutrition, School of Nutritional Science and Dietetics, Tehran University of Medical Sciences, P. O. Box 14155/6117, Tehran, Iran

Full list of author information is available at the end of the article
}

disease and mortality [3-6] and thereby has imposed a substantial financial burden either in developed or in developing countries [7]. Traditionally, obesity has been thought to be a consequence of positive energy balance [8]. However, there is evidence that intake of some food groups, independent of total energy intake, may be associated with the risk of adiposity $[9,10]$.

In general, food groups are consumed in different combinations called dietary patterns. Dietary patterns are combinations of foods or food groups that are different from dietary behaviours, which are related to behaviors such as skipping meals, snacking, drinking sweetened original author(s) and the source, provide a link to the Creative Commons licence, and indicate if changes were made. The images or other third party material in this article are included in the article's Creative Commons licence, unless indicated otherwise in a credit line to the material. If material is not included in the article's Creative Commons licence and your intended use is not permitted by statutory regulation or exceeds the permitted use, you will need to obtain permission directly from the copyright holder. To view a copy of this licence, visit http://creativecommons.org/licenses/by/4.0/. The Creative Commons Public Domain Dedication waiver (http://creativeco mmons.org/publicdomain/zero/1.0/) applies to the data made available in this article, unless otherwise stated in a credit line to the data. 
beverages, and eating fast food. The major identified data-driven dietary patterns are Western-style dietary pattern, rich in red and processed meat, refined grains, and high fat dairy, as well as Prudent or healthy dietary pattern rich in fruit and vegetables, whole grains, fish, and low fat dairy $[11,12]$.

It is proposed that dietary patterns represent a broader perspective of food and nutrient consumption, and may thus be more predictive of disease risk than individual foods or nutrients [13]. Dietary pattern analyses are increasingly used to investigate diet-disease associations [14]. It has been shown that higher adherence to a healthy diet may be associated with a lower likelihood of adiposity and in contrast, adopting a Western-style dietary pattern may promote adiposity [15-20].

Data-reduction statistical methods such as principal component (PCA) [21] or cluster analysis [22] and reduced rank regression [23] are useful techniques that have been frequently used to characterize patterns of dietary intake considering potential inter-relations between food groups [24]. A recent umbrella review indicated that PCA is the most common statistical approach to characterize patterns of dietary intake [14], because it considers correlation or covariance existed between food groups to create uncorrelated linear combinations entitled components or patterns [25].

However, PCA and other common statistical methods do not demonstrate pairwise correlation between food groups. Gaussian graphical model (GGM) is recently used as an innovative approach exploring patterns of dietary intake [26]. This graphical method shows the pairwise correlation between food groups, independent of the effects of other food groups [27], and thereby can show that how food groups are consumed in relation to one another [26]. The conditional independence analysis constructs the networks of foods that shows the underlying structure of the dataset. This method presents a graphical perspective from the link between food groups and identifies dietary networks representing patterns of dietary intake [28].

GGM is a novel statistical approach to explore patterns of dietary intake. However, patterns identified through this method have not been investigated in relation to the risk of adiposity. In addition, Iranian eating habits are changing rapidly towards a Western-style eating pattern [29]. GGM can show food groups that are central to the potentially healthy and unhealthy dietary networks and thus, can help determine what food groups are the main constructors of dietary patterns. This information cannot be obtained by other data-driven approaches and can help developing more efficient dietary guidance to prevent rising trend in adherence to Western dietary patterns in Iran. In this study, we, therefore, aimed to describe dietary networks identified by GGM, representing patterns of dietary intake in a sample of Iranian adults and to investigate the potential association of these dietary patterns with general and abdominal adiposity.

\section{Materials and methods Study participants}

The present cross-sectional study was performed in Tehran, capital of Iran, from 2018 to 2019. The formula used for sample size calculation was as follows: $n=(\mathrm{pqz} 2) /$ E2 [30, 31]. Considering the prevalence of overweight and obesity in Tehranian adults (65\%) [32], an error coefficient of $d=0.04$ and at $\alpha$ level of 0.05 , the sample size of 546 participants was obtained. With a design effect of 1.5 and to compensate for the potential exclusion of participants due to under- and over-reporting of total energy intake, or attrition due to other reasons, the final sample size of 850 participants was selected for inclusion.

For recruitment of participants, the following criteria were applied: apparently healthy men and women, aged 20 to 59 years who attended the local health care centers during the study period and had the willingness to take part in the study. Apparently healthy was defined as adults without existing non-communicable chronic diseases including cardiovascular disease, type 2 diabetes, cancers, and respiratory, renal, and autoimmune disorders.

A two-stage cluster sampling was used for the recruitment of participants from healthcare centers. First, a list of all healthcare centers that existed in five districts of the city (North, South, East, West and center) was provided. Then we randomly chose eight health centers from each district ( 40 health centers). Finally, to obtain the number of participants in each health center, we divided the total sample size (850) by the number of health centers (40).

\section{Ethical approval}

The ethical committee of the Tehran University of Medical Sciences approved the study protocol and informed consent form (Ethic Number: IR.TUMS.VCR. REC.1397.157). All patients received written information regarding the background and procedures of the study and gave written informed consent before entering the study.

\section{Data collection}

Through a face-to-face interview, participant's demographic characteristics were obtained by using prespecified data extraction forms. A trained interviewer completed a questionnaire designed to assess the participants' demographics including age (year), gender, educational level (illiterate, under diploma, diploma, educated), marital status (married or other [not married or 
divorced]), occupation (employed, retired, house-keeper, or unemployed), and smoking status (never smoked, former smoker, current smoker).

\section{Dietary assessment}

Dietary intake was assessed by using a reliable and validated 168-item food frequency questionnaire [33]. During a private face-to-face interview and by a trained dietitian, the frequency (daily, weekly, monthly, and yearly) and amount of each food item during the past year was recorded. Dietary intakes were then converted to $\mathrm{g} / \mathrm{d}$ according to household measures [34]. Intake of energy and nutrient content of foods was estimated by using Nutritionist IV software based on the US Department of Agriculture food composition database modified for Iranian foods [35].

\section{Physical examinations}

Weight was measured using a digital adult scale (Seca model 808, measurement accuracy $+/-100 \mathrm{~g}$ ) [36]. Participant's height was measured unshod using a wall stadiometer with a precision of $1 \mathrm{~cm}$ (Seca, Germany) [36]. BMI was calculated as weight divided by the square of height $\left(\mathrm{kg} / \mathrm{m}^{2}\right)$. Waist circumference was measured with a tape measure to the nearest $0.1 \mathrm{~cm}$ between the iliac crest and the lowest rib during exhalation. Hip circumference was recorded below the iliac crest, by measuring the maximum circumference around the buttocks and then, waist-to-hip ratio (WHR) was calculated.

Physical activity was assessed by using the International Physical Activity Questionnaire [37] and was recorded as metabolic equivalent minutes per week (MET-min/ week) [38]. Participants were grouped into two categories including "no or low physical activity" (<3000 MET-min/ week) and "moderate or high physical activity" (>3000 MET-min/week).

\section{Definition of general and abdominal adiposity}

General adiposity was defined as $B M I \geq 30 \mathrm{~kg} / \mathrm{m}^{2}$ [39]. Central adiposity was defined as follow: waist circumference greater than $102 \mathrm{~cm}$ for men and $88 \mathrm{~cm}$ for women [40], and WHR greater than 0.90 for men and 0.85 for women [41].

\section{Statistical analysis}

GGM was used to explore networks of dietary intake of participants. These types of statistical analyses are a class of methods that are increasingly used for exploratory analysis [42]. GGMs are graphical models that show the conditional independence structure in the data set by assessing the pairwise correlation between two variables controlling for others. GGMs assume a multivariate normal distribution for underlying data and can infer a direct relation between variables in a given data set without prior knowledge [43]. The use of GGMs for exploring conditional independence structures between food intake variables is an emerging and promising approach.

For the purpose of the present study, dietary intakes of participants were classified into 35 food groups (Table 1). The analysis of GGM was performed in R (version 3.4.3, R) [44]. A sparse inverse covariance (precision) matrix was estimated from the data using graphical lasso (least absolute shrinkage and selection operator) in $\mathrm{R}$ package "glasso" [26]. Communities, sets of closely related links, were detected within all identified networks to facilitate interpretation using the $\mathrm{R}$ package "linkcomm", which can detect nested and overlapping communities in networks [45].

GGM-derived dietary networks consist of nudes and edges. Nudes indicate food or food groups. Edges show conditional dependencies between food groups indicated by partial correlation coefficients. The width of the edges indicates the strength of the correlations that existed between food groups. Partial correlations $\geq \pm 0.20$ were considered strong [46]. Continuous lines represent positive partial correlations and broken lines represent negative partial correlations. Communities were indicated by nodes and edges of the matching color. A combination of three or more nudes that were related to each other formed a dietary network. The absence of an edge between food groups indicates

Table 1 List of food groups included in the analysis of GGM to derive dietary networks

\begin{tabular}{llll}
\hline $\mathbf{n}$ & Food groups & $\mathbf{n}$ & Food groups \\
\hline 1 & Red meat & 19 & Grains \\
2 & Processed meat & 20 & Nuts \\
3 & Organ meat & 21 & Legumes \\
4 & Fish & 22 & Snacks \\
5 & Low-fat diary & 23 & Salty snacks \\
6 & High-fat dairy & 24 & Cookies/cake \\
7 & Fresh fruit & 25 & Pickles and flavors \\
8 & Dried fruit & 26 & Cheeps/puff \\
9 & Canned fruit & 27 & Sugar sweetened \\
& & & beverages (drinks) \\
10 & Fruit juices (100\%) & 28 & Sauces \\
11 & Raw vegetables & 29 & Butter \\
12 & Cooked vegetables & 30 & Margarine \\
13 & Cabbages & 31 & Animal fat \\
14 & Garlic & 32 & Vegetable oils \\
15 & Mushroom & 33 & Egg \\
16 & Other vegetables & 34 & Tea \\
17 & Potatos & 35 & Coffee \\
18 & Side dish & & \\
\hline
\end{tabular}


conditional independence considering all other variables [47]. Food groups that belonged to more than one community were evaluated for centrality to determine the potential importance of a food group based on the number of communities it belongs to [48].

To investigate the link between GGM-derived dietary networks and adiposity in the participants, all major networks were scored. For this purpose, dietary intake variables included in each network were standardized to the same mean (i.e., ' 0 ') and 1 standard deviation. In the second step, standardized intakes of food groups were multiplied by their factor loading scores (positive or negative) obtained by PCA. Then, the score of food groups within each network was added together to calculate network scores. The network scores were then categorized in tertiles and the characteristics of participants across tertiles of dietary networks were compared using $\mathrm{X} 2$ for categorical variables and ANOVA test for continuous variables. The odds ratios (ORs) and $95 \%$ confidence intervals (CIs) of general and abdominal adiposity across tertiles of network scores were estimated using logistic regression analysis controlling for age, sex, physical activity, smoking status, marital status, energy intake and menopausal status (for women). The analyses were performed using SPSS software, version 22 (SPSS Inc., Chicago, IL, USA). A two-sided $p$-value $<0.05$ was considered significant.

\section{Results}

The present cross-sectional study included 850 adults, of whom $69 \%$ were women. The general characteristics of the study participants are presented in Table 2. Participants were on mean $44.7 \pm 10.8$ years old and the mean BMI was $27.8 \pm 5.6 \mathrm{~kg} / \mathrm{m}^{2}$. There is no difference in terms of age and BMI across either sex. The mean energy intake was $2586 \pm 1140 \mathrm{kcal} / \mathrm{d}$. The majority of participants were nonsmoker (91\%) and had a sedentary lifestyle $(<3000$ MET-min/week) (63\%).

\section{Characteristics of dietary networks identified by GGM}

GGM analysis identified three major networks of dietary intake (Fig. 1), where 30 foods were grouped into six communities. The identified networks were healthy, unhealthy and saturated fats networks, wherein cooked vegetables, processed meat and butter were, respectively, central to the networks (Fig. 2). The central situation of the aforementioned food groups indicates their important position in the identified dietary networks.

The healthy dietary network is composed of two communities, where cooked vegetables was central to the network (Fig. 2). Starting in the upper left, the first community consisted of cooked vegetables, mushrooms, grains, legumes and baked potato, where almost all foods were partially correlated to each other. The network indicated that the intake of a baked potato was conditionally dependent on the intake of cooked vegetables (partial correlation $=0.14$ ). The second community in the upper

Table 2 General characteristics of the study participants $(n=850)$

\begin{tabular}{llll}
\hline Variable $^{\mathbf{a}}$ & Total population, $\boldsymbol{n = 8 5 0}$ & Women, $\boldsymbol{n}=\mathbf{5 8 4}$ & Men, $\boldsymbol{n = 2 6 6}$ \\
\hline Age (years) & $44.7 \pm 10.8$ & $44.5 \pm 11.1$ & $45.2 \pm 10.1$ \\
Body weight (Kg) & $73.4 \pm 13.5$ & $70.2 \pm 11.8$ & $80.6 \pm 14.3$ \\
Height (cm) & $162.0 \pm 8.9$ & $159.0 \pm 7.2$ & $170.0 \pm 7.2$ \\
BMI (kg/m ${ }^{2}$ ) & $27.8 \pm 5.6$ & $27.9 \pm 6.1$ & $27.6 \pm 4.1$ \\
Waist circumference (cm) & $92.0 \pm 12.4$ & $90.5 \pm 12.3$ & $95.3 \pm 12.0$ \\
WHR (unit) & $0.88 \pm 0.11$ & $0.86 \pm 0.13$ & $0.90 \pm 0.12$ \\
Physical activity (\% low) & $63 \%$ & $65 \%$ & $61 \%$ \\
Education (\% educated) & $34.3 \%$ & $41.9 \%$ & $38.0 \%$ \\
Occupation (\% employed) & $26 \%$ & $19.3 \%$ & $40.2 \%$ \\
Smoking status (\% current) & $5.2 \%$ & $1.8 \%$ & $12.4 \%$ \\
Marital status (\% married) & $80.9 \%$ & $77.2 \%$ & $89.1 \%$ \\
Post-menopausal (\%) & - & $27.8 \%$ & - \\
Dietary intake & & & $2487 \pm 1146$ \\
$\quad$ Energy (kcal/d) & $2586 \pm 1140$ & $2745 \pm 1120$ & $343 \pm 150$ \\
Carbohydrate (g/d) & $354 \pm 153$ & $380 \pm 155$ & $80.2 \pm 51.5$ \\
Fat (g/d) & $82.3 \pm 51.3$ & $86.7 \pm 50.1$ & $83.3 \pm 51.0$ \\
Protein (g/d) & $86.4 \pm 48.0$ & $93.2 \pm 39.7$ & \\
\hline
\end{tabular}

Abbreviations: $B M I$ body mass index, $D B P$ diastolic blood pressure, SBP systolic blood pressure, WHR waist-to-hip ratio

${ }^{a}$ Values are mean \pm standard deviation for continuous variables and (\%) for categorical variables 


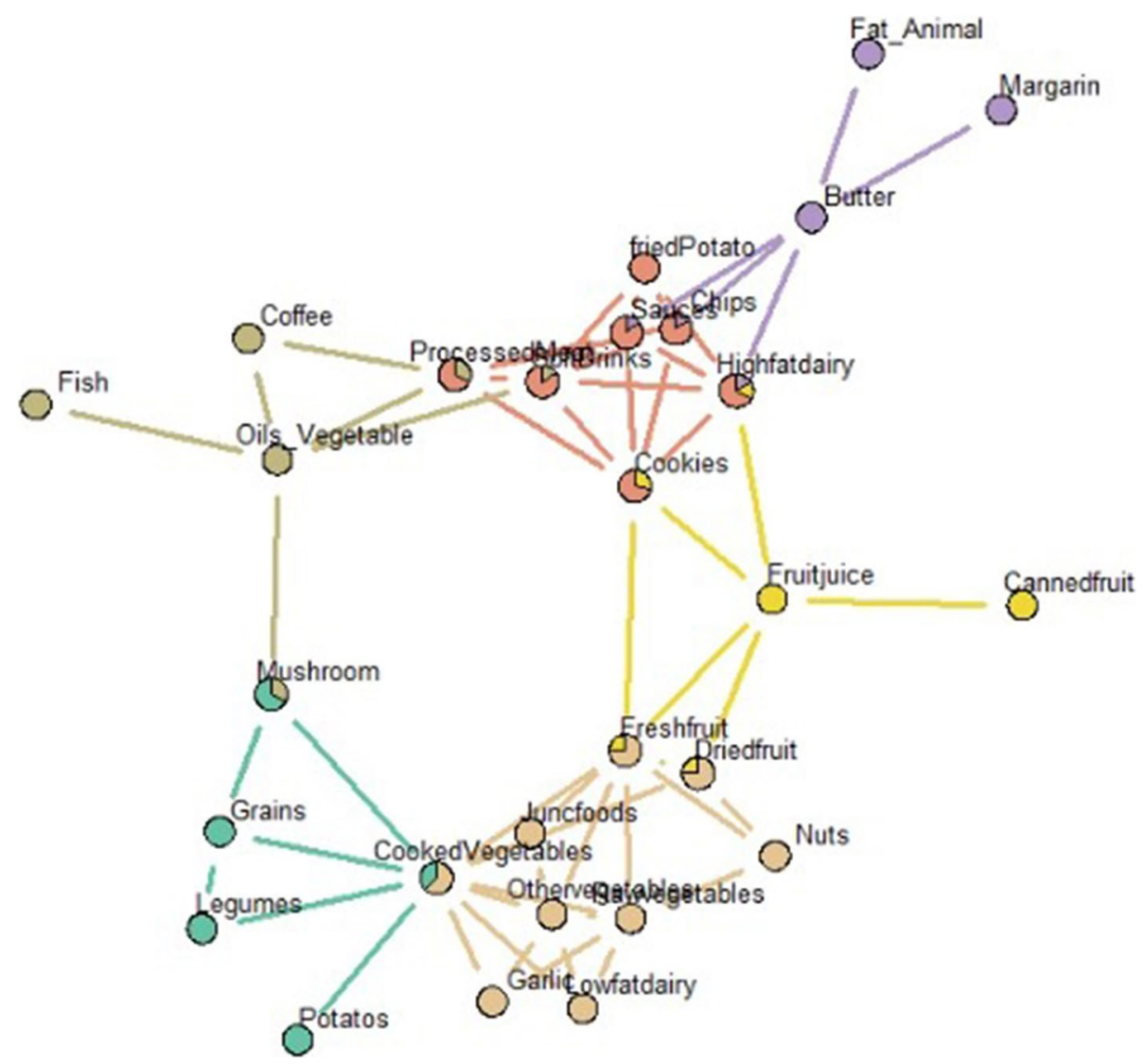

Fig. 1 Dietary networks identified through Gaussian graphical model in Iranian adults $(n=850)$

right was composed of nine food groups, among which there was a strong positive correlation between fresh fruit and raw vegetables (partial correlation $=0.30$ ). There was also a slight negative correlation between raw vegetables and nuts (partial correlation $=-0.05$ ), fresh fruit and cooked vegetables (partial correlation $=-0.10$ ), and side dish and dried fruit (partial correlation $=-0.005$ ).

Another network identified in the participants was an unhealthy network and was made of three communities (Fig. 2). The network showed a central role of processed meat. The first community in the lower-left composed of five foods, wherein there was a strong positive correlation between vegetable oils and fish and processed meat (partial correlations $=0.99$ and 0.97 , respectively). There was also a slight negative correlation between vegetable oils and coffee and soft drinks (partial correlations $=-0.05$ and -0.16 , respectively). The network indicated that the intake of fish was conditionally dependent on the intake of vegetable oils. There were also two relatively overlapping communities in the unhealthy network. The central community consisted of processed meat, fried potatoes, soft drinks, sauces, cookies and cakes, chips, and highfat dairy products, wherein food groups were positive albeit weakly correlated to each other. The third community was made of cookies and cakes, high-fat dairy, fruit juices and canned fruit. The network indicated that the intake of canned fruit was conditionally dependent on the intake of fruit juices.

The third network in the lower right consisted of butter, animal fat, and margarine that were linked by slight positive correlations (Fig. 2). The saturated fats network indicated that the intake of animal fat and margarine was conditionally dependent on the intake of butter (partial correlations $=0.03$ and 0.06 , respectively). Butter was also central to the network.

Characteristics of the study participants across tertiles of dietary networks are presented in Table 3. There is no difference in terms of age, sex, anthropometric measures, physical activity levels, education level, and other characteristics across tertiles of identified dietary networks.

Table 4 shows the association between the GGMderived dietary networks and likelihood of general and abdominal adiposity in the study participants. Higher adherence to GGM-derived healthy, unhealthy, and saturated fats networks was not associated with likelihood 


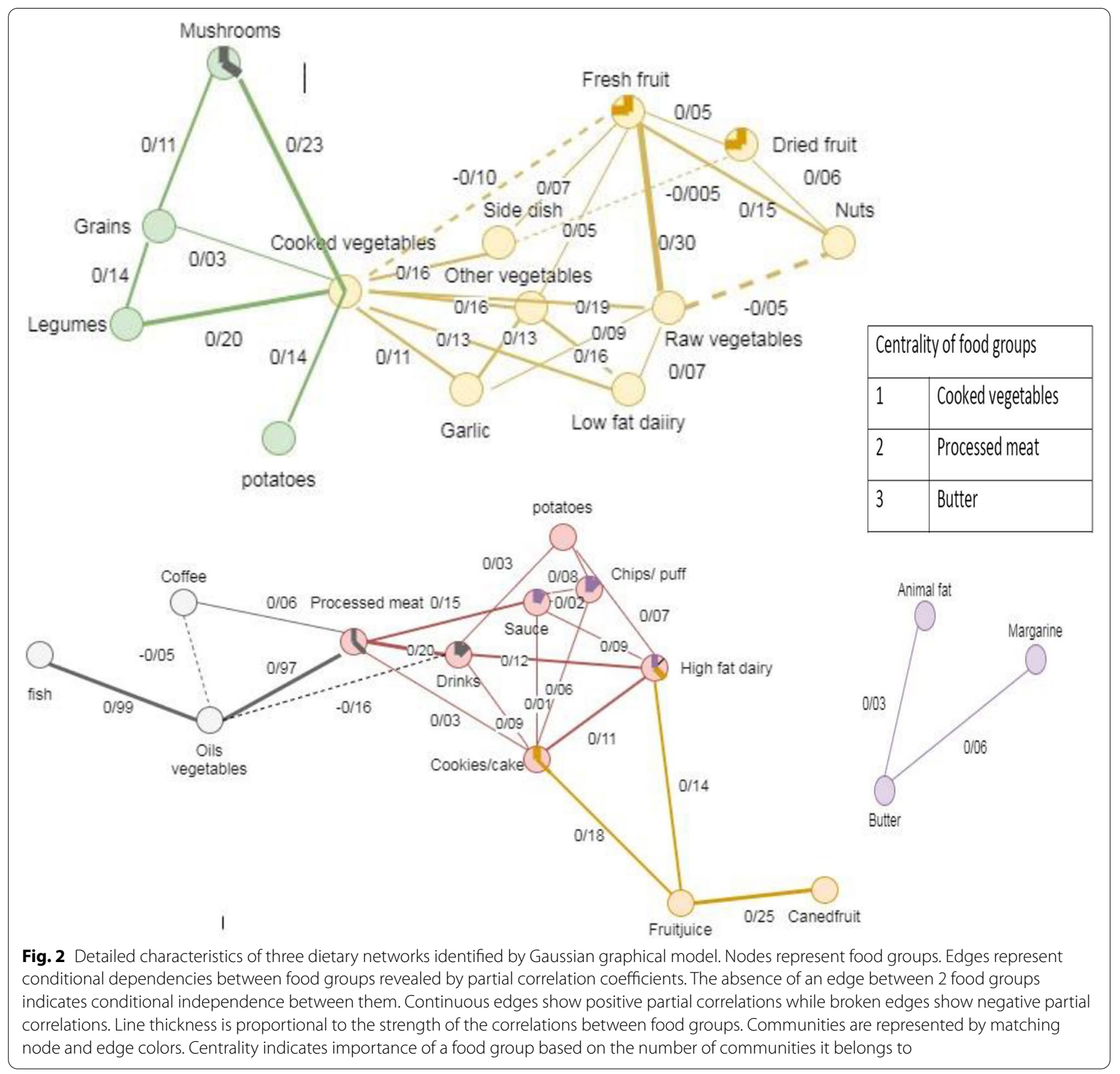

of general adiposity. Being in the second (OR: 1.43, 95\%CI: $0.99,2.09$ ) or third (OR: $1.37,95 \%$ CI: $0.94,2.01$ ) tertiles of unhealthy dietary network score was not related to the odds of having abdominal obesity, defined by increased waist circumference $(P$ for trend $=0.09$ ). In addition, being the third tertile of GGM-derived saturated fats network score was associated with higher odds of abdominal adiposity as assessed by WHR, either in the crude (OR: 1.61, 95\%CI: $1.16,2.25 ; P$ for trend $=0.004$ ) or in the maximally adjusted model (OR: 1.56, 95\%CI: 1.08, 2.25; $P$ for trend $=0.01$ ).

\section{Discussion}

In the present cross-sectional study, we investigated the link between GGM-derived dietary networks and likelihood of general and abdominal adiposity in a sample of Iranian adults. The results suggested that being in the top tertile of saturated fat network score was strongly associated with the chance of having central adiposity as defined by WHR. There was also a non-significant positive association between higher adherence to the unhealthy dietary network and central adiposity as assessed by waist circumference. There was no association between unhealthy and saturated fats networks and 


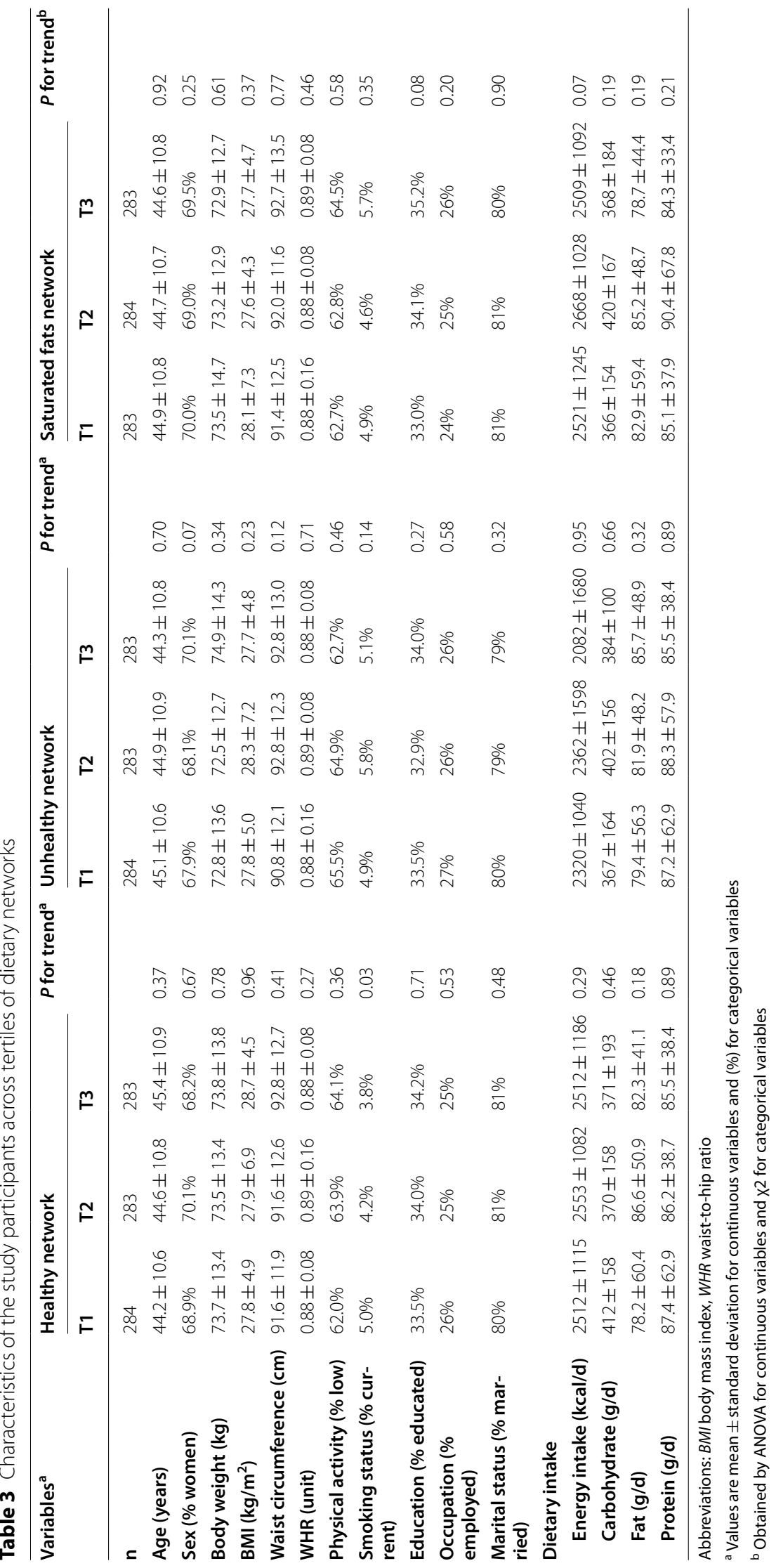


Table 4 The association between dietary networks and general and central adiposity ${ }^{\mathrm{a}}$

\begin{tabular}{|c|c|c|c|c|}
\hline Dietary networks & Tertile 1 & Tertile 2 & Tertile 3 & $P$ for trend $d^{b}$ \\
\hline \multicolumn{5}{|l|}{$\mathrm{BMI} \geq 30 \mathrm{~kg} / \mathrm{m}^{2}$} \\
\hline \multicolumn{5}{|l|}{ Healthy network } \\
\hline Crude & 1.0 & $0.98(0.68,1.41)$ & $0.98(0.68,0.41)$ & 0.92 \\
\hline Adjusted & 1.0 & $1.08(0.74,1.58)$ & $1.01(0.69,1.46)$ & 0.95 \\
\hline \multicolumn{5}{|c|}{ Unhealthy network } \\
\hline Crude & 1.0 & $0.82(0.57,1.19)$ & $0.94(0.66,1.35)$ & 0.76 \\
\hline Adjusted & 1.0 & $0.79(0.54,1.15)$ & $0.99(0.68,1.44)$ & 0.96 \\
\hline \multicolumn{5}{|c|}{ Saturated fats network } \\
\hline Crude & 1.0 & $0.98(0.68,1.42)$ & $1.01(0.70,1.45)$ & 0.92 \\
\hline Adjusted & 1.0 & $0.91(0.62,1.34)$ & $0.99(0.68,1.44)$ & 0.98 \\
\hline \multicolumn{5}{|c|}{$W C>102 \mathrm{~cm}$ in men and $88 \mathrm{~cm}$ in women } \\
\hline \multicolumn{5}{|c|}{ Healthy network } \\
\hline Crude & 1.0 & $0.84(0.60,1.17)$ & $1.20(0.86,1.67)$ & 0.27 \\
\hline Adjusted & 1.0 & $0.95(0.63,1.32)$ & $1.30(0.89,1.89)$ & 0.14 \\
\hline \multicolumn{5}{|c|}{ Unhealthy network } \\
\hline Crude & 1.0 & $1.36(0.98,1.90)$ & $1.14(0.82,1.59)$ & 0.42 \\
\hline Adjusted & 1.0 & $1.43(0.99,2.09)$ & $1.37(0.94,2.01)$ & 0.09 \\
\hline \multicolumn{5}{|c|}{ Saturated fats network } \\
\hline Crude & 1.0 & $1.02(0.73,1.42)$ & $1.15(0.82,1.59)$ & 0.40 \\
\hline Adjusted & 1.0 & $0.92(0.63,1.34)$ & $1.20(0.83,1.75)$ & 0.29 \\
\hline \multicolumn{5}{|c|}{ WHR $>0.90$ for men and 0.85 for women } \\
\hline \multicolumn{5}{|c|}{ Healthy network } \\
\hline Crude & 1.0 & $1.23(0.88,1.72)$ & $1.16(0.86,1.67)$ & 0.27 \\
\hline Adjusted & 1.0 & $1.34(0.93,1.93)$ & $1.18(0.82,1.70)$ & 0.34 \\
\hline \multicolumn{5}{|c|}{ Unhealthy network } \\
\hline Crude & 1.0 & $1.25(0.90,1.74)$ & $1.12(0.81,1.56)$ & 0.47 \\
\hline Adjusted & 1.0 & $1.19(0.82,1.70)$ & $1.03(0.71,1.48)$ & 0.85 \\
\hline \multicolumn{5}{|c|}{ Saturated fats network } \\
\hline Crude & 1.0 & $1.10(0.79,1.53)$ & $1.61(1.16,2.25)$ & 0.004 \\
\hline Adjusted & 1.0 & $1.05(0.73,1.50)$ & $1.56(1.08,2.25)$ & 0.01 \\
\hline
\end{tabular}

Abbreviations: $B M I$ body mass index, WC waist circumference, WHR waist-to-hip ratio

${ }^{a}$ Data are expressed as odds ratio and $95 \%$ confidence interval

${ }^{b}$ Obtained by logistic regression analysis, controlling for age, sex, occupation, smoking status, education, marital status, menopausal status, physical activity, and energy intake

the likelihood of general adiposity. Higher adherence to the healthy dietary network was not related to general and central obesity.

Our results regarding the association of unhealthy and saturated fats dietary networks and central obesity are consistent with those of previous studies. Previous research showed a similar association between unhealthy dietary patterns, identified by other statistical approaches such as PCA or factor analysis, and central obesity. A cross-sectional study in Iranian female teachers in Tehran indicated that higher adherence to a factor analysis-derived Western-style dietary pattern rich in red and processed meat, fried potato, butter, high-fat dairy, refined grains, sugar-sweetened beverages and pizza was associated with higher odds of central obesity [49]. The GGM-identified unhealthy network in our study was composed of several components similar to the Westernstyle dietary pattern reported by Esmaillzadeh et al. [49]. Both studies were conducted on Tehranian adults. However, our unhealthy pattern also included other foods as well, such as sauce, chips, coffee, vegetable oil and canned fruit.

A cross-sectional study in Canada applied factor analysis to derive patterns of dietary intake. The analyses indicated that a Western dietary pattern, defined by higher consumption of French fries, condiments, red and processed meats, refined grains, and regular soft drinks, was associated with larger waist circumference and WHR 
[50]. Heidemann et al. reported that higher adherence to factor analysis-derived processed food pattern, rich in high-sugar beverages, sweets and cakes, snacks, refined grains, potatoes, red and processed meat, eggs, beer, and butter was positively associated with abdominal adiposity within a nationally representative sample of $4000 \mathrm{Ger}-$ man adults [51].

The Thai National Health Examination Survey IV indicated that factor analysis-derived meat pattern, characterized by a high intake of red and processed meat and fried foods, was associated with abdominal obesity in men, but not in women [52]. A baseline evaluation within a cohort study in the Mexican adults' population indicated that a high protein, high-fat diet, characterized by a high factor loading score of red and processed meat, poultry, egg, and butter was positively associated with abdominal adiposity [53]. However, there is inconsistent evidence. A cross-sectional investigation in Lebanese adults in the Middle East failed to show an association between unhealthy dietary patterns, derived by factor analysis, and central obesity [54]. Other cross-sectional studies have reported similar null associations [55-57]. The inconsistent findings across studies may be due to different components of identified dietary patterns, different tools used to assess dietary intake, and different adjustment models.

Our GGM-derived unhealthy network shared similarities with components of unhealthy patterns identified in the aforementioned studies. In particular, two population-based investigations in Tehranian adults in Iran identified similar Western/unhealthy dietary patterns $[49,58]$. In a population-based cross-sectional study in Tehranian female teachers, through factor analysis, authors identified a Western-type dietary pattern rich in red and processed meat, high-fat dairy, fried potato, refined grains, egg, sugar-sweetened beverages, and butter [49]. We also found a similar unhealthy network, with some additional components such as coffee, canned fruit, and sauce. In the Tehran Lipid and Glucose Study involving 1630 Tehranian adults, a PCA-derived high-fat, high sugar dietary pattern was identified, characterized by high intake of mayonnaise, butter, solid oil, sweet and salty snack, coffee, soda, high-fat dairy, and pizza [58], which was comparable with our GGM-identified saturated fats network.

Our GGM-derived healthy dietary network was also similar to factor analysis- and PCA-derived dietary patterns identified in other population-based studies in Tehran. Through factor analysis, a healthy dietary pattern rich in whole grains, fruit, vegetables, legumes, low-fat dairy, fish, and poultry was identified in Tehranian adults [49]. We also found other healthy food as well, such as nuts in our GGM-derived healthy network. In another population-based study in Tehran, a PCA-derived healthy dietary pattern, rich in fruit, vegetables, low-fat dairy, and dried fruit, was identified [58].

These results indicated that GGM can be used as a complementary approach to identify dietary networks reflecting patterns of dietary intake. A population-based cohort study in Germany indicated that GGM-derived dietary networks reflect dietary patterns and could be used to investigate diet-disease associations [28]. GGM describes internal patterns representing networks and indicates key interrelated food groups that may be potential candidates for further diet-disease investigations. In addition, GGM can show that how food groups are consumed in different combinations, which may be useful for interpreting the dietary patterns of the population. In contrast to traditional statistical approaches such as PCA or factor analysis, each food or food group can only be part of a specific dietary network at a time.

One of the main advantages of GGM is that it can identify food groups that are central to the networks. As presented above, Iranian eating habits are changing rapidly towards a Western-style eating pattern [29]. GGM can show food groups that are central to the potentially healthy and unhealthy dietary networks and thus, can help determine what food groups are the main constructors of the dietary patterns. For example, our analyses indicated that processed meat and butter are the two food groups that are central to the unhealthy dietary patterns in a sample of Tehranian adults. This information cannot be obtained by other data-driven approaches and can help developing more efficient dietary guidance to prevent the growing rise in Western dietary patterns in Iran.

Another advantage of GGM compared to traditional methods for exploring dietary patterns is links between food groups. Our saturated fat dietary network indicated correlations between butter, animal fat, and margarine, suggesting that these foods were consumed in relation to each other. These information can be used for identifying consumption probabilities of the foods identified in the network for each individual. Such probabilities would be helpful for modeling alternative intake patterns by modifying intake probabilities, which may help assess the impact of dietary behavior change or dietary recommendations.

In addition, our analyses revealed that processed meat consumption is central to the unhealthy dietary intake in the population studied in this research. GGM underscored its importance and presented the pattern of its consumption, i.e., how it is consumed in relation to other foods. The networks indicated positive correlations between processed meat and vegetable oils, drinks, high fat dairy, and sauce. This is interesting because the role 
of red meat for health outcomes is still a research agenda priority $[59,60]$.

There are some potential mechanisms to explain the associations observed in our study. The higher likelihood of central obesity observed in participants with high unhealthy and saturated fats network scores could be related to lower consumption of healthy foods and protective nutrients [17]. In addition, the saturated fat network is composed of dietary sources of saturated fats such as animal fats, butter, and margarine. The unhealthy network was also made of foods rich in saturated fats such as red and processed meats and high-fat dairy. There is evidence that high saturated fat intake through exerting unfavorable impacts on gut microbiota composition [61], inducing obesity-related gene expression [62], and reducing fat oxidation and daily energy expenditure [63], can accelerate adiposity. High saturated fat intake promotes insulin resistance and low-grade systemic inflammation, the two potential obesity-inducing pathophysiological mechanisms [63]. The 2008 report of the third FAO (Food and Agriculture Organization of the United Nations)/WHO (World Health Organization) Expert Consultation on Fats and Fatty Acids in Human Nutrition highlighted the need for shifting from fat quantity to quality [64]. The 2015 US Dietary Guidelines Advisory Committee (DGAC) report issued that it is more important to optimize types of dietary fat than reducing total fat [65].

The present cross-sectional study had several strengths. To our knowledge, this is the first population-based study to investigate the association between GGM-derived dietary networks, representing patterns of dietary intake, and general and abdominal adiposity in adults. Our results showed that GGM can be used as a supplementary approach for identifying eating patterns. We used trained dietitians and valid tools to obtain information from participants. In addition, we recruited a relatively large number of participants. Additionally, GGM minimizes the subjective choices when analyzing data for identifying dietary patterns and thereby, presents robust results.

There were also some important limitations for consideration. We did not identify meal-specific dietary networks and thus, future research can focus on the properties of meal-based dietary networks. We used a food frequency questionnaire for dietary assessment that has been shown to have some limitations in evaluating dietary information [66]. The cross-sectional design of our study is another limitation that highlights the need for prospective studies to confirm the findings. Finally, due to the lack of consumption of whole grains in the Iranian diet, we did not include whole grains in the GGM analysis.

\section{Conclusions}

The present cross-sectional study describes GGMderived dietary networks reflecting dietary patterns in a sample of Iranian adults. Our results indicated that being in the top tertile of saturated fat network scores was associated with a higher odds of abdominal adiposity. There was no association between dietary networks and general adiposity. GGM can show that how food groups are consumed in relation to one another and can determine food groups that are central to the dietary networks. This method shows the underlying structure of the dataset and thus, presents a graphical perspective from the link between food groups. This information could be used to present a better understanding of the construction of dietary patterns and can help to present more useful dietary guidance.

\section{Abbreviations}

BMI: Body mass index; GGM: Gaussian graphical model.; PCA: Principal component analysis; WHR: Waist-to-hip ratio.

\section{Acknowledgements \\ We thank Dr. Khalid Ighbal, Khyber Medical University, Peshawar, Pakistan, for helping us with the statistical analyses in R. We thanks all those who partici- pated in this study.}

\section{Authors' contributions}

SS-B and KDJ conceived and designed the study, AJ and NJ performed data acquisition and completed the questionnaires, SS-B and MSY performed the analyses, AJ and SS-B wrote the first draft of the manuscript, SS-B, KDJ and MSY critically revised the manuscript, KDJ received financial support for undertaking this study, and all authors have read and approved the final manuscript. SS-B in the guarantor.

\section{Funding}

This maunuscript has been granted by Tehran University of Medical Sciences (Grant No: 40186). The funder had no role in the design, analysis or writing of this article.

\section{Availability of data and materials}

The datasets used and/or analyzed during the current study are available from the corresponding author on reasonable request.

\section{Declarations}

Ethics approval and consent to participate

This study was conducted according to the guidelines laid down in the Declaration of Helsinki and all procedures involving research study participants were approved by the ethics committee of Tehran University of Medical Sciences. Written informed consent was obtained from all subjects/patients.

Consent for publication

Not applicable.

\section{Competing interests}

The authors declare that they have no competing interests.

\section{Author details}

${ }^{1}$ Food Safety Research Center (salt), Semnan University of Medical Sciences, Semnan, Iran. ${ }^{2}$ Department of Community Nutrition, School of Nutritional Science and Dietetics, Tehran University of Medical Sciences, P. O. Box 14155/6117, Tehran, Iran. ${ }^{3}$ Department of Clinical Nutrition, School of Nutritional Science and Dietetics, Tehran University of Medical Sciences, 
Tehran, Iran. ${ }^{4}$ Department of Epidemiology and Biostatistics, School of Public Health, Tehran University of Medical Sciences, Tehran, Iran.

Received: 1 April 2021 Accepted: 15 October 2021

Published online: 27 October 2021

\section{References}

1. Abarca-Gómez L, Abdeen ZA, Hamid ZA, Abu-Rmeileh NM, Acosta-Cazares $B$, Acuin $C$, et al. Worldwide trends in body-mass index, underweight, overweight, and obesity from 1975 to 2016: a pooled analysis of 2416 population-based measurement studies in 128.9 million children, adolescents, and adults. Lancet. 2017;390(10113):2627-42.

2. Chooi YC, Ding C, Magkos F. The epidemiology of obesity. Metabolism. 2019;92:6-10

3. Jayedi A, Rashidy-Pour A, Khorshidi M, Shab-Bidar S. Body mass index, abdominal adiposity, weight gain and risk of developing hypertension: a systematic review and dose-response meta-analysis of more than 2.3 million participants. Obes Rev. 2018;19(5):654-67.

4. Jayedi A, Rashidy-Pour A, Soltani S, Zargar MS, Emadi A, Shab-Bidar S. Adult weight gain and the risk of cardiovascular disease: a systematic review and dose-response meta-analysis of prospective cohort studies. Eur J Clin Nutr. 2020;74(9):1263-75.

5. Jayedi A, Soltani S, Zargar MS, Khan TA, Shab-Bidar S. Central fatness and risk of all cause mortality: systematic review and dose-response metaanalysis of 72 prospective cohort studies. BMJ. 2020;370.

6. Vazquez G, Duval S, Jacobs DR Jr, Silventoinen K. Comparison of body mass index, waist circumference, and waist/hip ratio in predicting incident diabetes: a meta-analysis. Epidemiol Rev. 2007;29(1):115-28.

7. Tremmel M, Gerdtham U-G, Nilsson PM, Saha S. Economic burden of obesity: a systematic literature review. Int J Environ Res Public Health. 2017;14(4):435.

8. Hill JO, Wyatt HR, Peters JC. Energy balance and obesity. Circulation. 2012;126(1):126-32

9. Rouhani M, Salehi-Abargouei A, Surkan P, Azadbakht L. Is there a relationship between red or processed meat intake and obesity? A systematic review and meta-analysis of observational studies. Obes Rev. 2014;15(9):740-8

10. Schlesinger S, Neuenschwander M, Schwedhelm C, Hoffmann G, Bechthold A, Boeing H, et al. Food groups and risk of overweight, obesity, and weight gain: a systematic review and dose-response meta-analysis of prospective studies. Adv Nutr. 2019;10(2):205-18.

11. Fung TT, Willett WC, Stampfer MJ, Manson JE, Hu FB. Dietary patterns and the risk of coronary heart disease in women. Arch Intern Med. 2001;161(15):1857-62.

12. van Dam RM, Rimm EB, Willett WC, Stampfer MJ, Hu FB. Dietary patterns and risk for type 2 diabetes mellitus in US men. Ann Intern Med. 2002;136(3):201-9.

13. Hu FB. Dietary pattern analysis: a new direction in nutritional epidemiology. Curr Opin Lipidol. 2002;13(1):3-9.

14. Jayedi A, Soltani S, Abdolshahi A, Shab-Bidar S. Healthy and unhealthy dietary patterns and the risk of chronic disease: an umbrella review of meta-analyses of prospective cohort studies. Br J Nutr. 2020;124(11):1133-44

15. Buckland G, Bach A, Serra-Majem L. Obesity and the Mediterranean diet: a systematic review of observational and intervention studies. Obes Rev. 2008;9(6):582-93.

16. Min M, Li-Fa X, Dong H, Jing W, Ming-Jie B. Dietary patterns and overweight/obesity: a review article. Iran J Public Health. 2017;46(7):869.

17. Rezagholizadeh F, Djafarian K, Khosravi S, Shab-Bidar S. A posteriori healthy dietary patterns may decrease the risk of central obesity: findings from a systematic review and meta-analysis. Nutr Res. 2017;41:1-13.

18. Ahmed FE, Gouda MM, Hussein LA, Ahmed NC, Vos PW, Mohammad MA. Role of melt curve analysis in interpretation of Nutrigenomics' MicroRNA expression data. Cancer Genomics Proteomics. 2017;14(6):469-81.

19. Gouda M, Moustafa A, Hussein L, Hamza M. Three week dietary intervention using apricots, pomegranate juice or/and fermented sour sobya and impact on biomarkers of antioxidative activity, oxidative stress and erythrocytic glutathione transferase activity among adults. Nutr J. 2015;15(1):1-10.
20. Shankar V, Gouda M, Moncivaiz J, Gordon A, Reo N, Hussein L, et al. Differences in gut metabolites and microbial composition and functions between Egyptian and US children are consistent with their diets. Msystems. 2017;2(1):e00169-16.

21. Gleason PM, Boushey CJ, Harris JE, Zoellner J. Publishing nutrition research: a review of multivariate techniques - part 3: data reduction methods. J Acad Nutr Diet. 2015;115(7):1072-82.

22. Devlin UM, MCNulty BA, Nugent AP, Gibney MJ. The use of cluster analysis to derive dietary patterns: methodological considerations, reproducibility, validity and the effect of energy mis-reporting. Proc Nutr Soc. 2012;71(4):599-609.

23. Weikert C, Schulze MB. Evaluating dietary patterns: the role of reduced rank regression. Curr Opin Clin Nutr Metab Care. 2016;19(5):341-6.

24. Schulze MB, Martínez-González MA, Fung TT, Lichtenstein AH, Forouhi NG. Food based dietary patterns and chronic disease prevention. BMJ. 2018;361:k2396. https://doi.org/10.1136/bmj.k2396.

25. Michels KB, Schulze MB. Can dietary patterns help us detect diet-disease associations? Nutr Res Rev. 2005;18(2):241-8.

26. Iqbal K, Buijsse B, Wirth J, Schulze MB, Floegel A, Boeing H. Gaussian graphical models identify networks of dietary intake in a German adult population. J Nutr. 2016;146(3):646-52.

27. Rasmussen MA, Bro R. A tutorial on the lasso approach to sparse modeling. Chemom Intell Lab Syst. 2012;119:21-31.

28. Iqbal K, Schwingshackl L, Floegel A, Schwedhelm C, Stelmach-Mardas M, Wittenbecher C, et al. Gaussian graphical models identified food intake networks and risk of type 2 diabetes, CVD, and cancer in the EPIC-Potsdam study. Eur J Nutr. 2019;58(4):1673-86.

29. Danaei G, Farzadfar F, Kelishadi R, Rashidian A, Rouhani OM, Ahmadnia S, et al. Iran in transition. Lancet. 2019;393(10184):1984-2005.

30. Payne G, Payne J. Key concepts in social research: sage; 2004.

31. Sarantakos S. Social research: Macmillan international higher education; 2012.

32. Kiadaliri AA, Jafari M, Mahdavi M-RV, Faghihzadeh S, Kalantari N, Asadi-Lari $M$. The prevalence of adulthood overweight and obesity in Tehran: findings from urban HEART-2 study. Med J Islam Repub Iran. 2015;29:178.

33. Mirmiran P, Esfahani FH, Mehrabi Y, Hedayati M, Azizi F. Reliability and relative validity of an FFQ for nutrients in the Tehran lipid and glucose study. Public Health Nutr. 2010;13(5):654-62.

34. Ghaffarpour M, Houshiar-Rad A, Kianfar H. The manual for household measures, cooking yields factors and edible portion of foods, vol. 7. Tehran: Nashre Olume Keshavarzy; 1999. p. 213.

35. Haytowitz D, Lemar L, Pehrsson P, Exler J, Patterson K, Thomas R, et al. USDA national nutrient database for standard reference, release 24. Washington, DC: US Department of Agriculture; 2011.

36. Lohman TG, Roche AF, Martorell R. Anthropometric standardization reference manual: human kinetics books; 1988.

37. Craig CL, Marshall AL, Sjöström M, Bauman AE, Booth ML, Ainsworth BE, et al. International physical activity questionnaire: 12-country reliability and validity. Med Sci Sports Exerc. 2003;35(8):1381-95.

38. Ainsworth BE, Haskell WL, Whitt MC, Irwin ML, Swartz AM, Strath SJ, et al. Compendium of physical activities: an update of activity codes and MET intensities. Med Sci Sports Exerc. 2000;32(9; SUPP/1):S498-504.

39. Organization WH. Obesity: preventing and managing the global epidemic. Geneva: World Health Organization; 2000.

40. Identification EPot, Overweight To, Adults Oi, Heart N, lung, institute B, diabetes Nlo, digestive, diseases K. Clinical guidelines on the identification, evaluation, and treatment of overweight and obesity in adults: the evidence report. New York: National Institutes of Health, National Heart, Lung, and Blood Institute; 1998.

41. Alberti KGMM, Zimmet PZ. Definition, diagnosis and classification of diabetes mellitus and its complications. Part 1: diagnosis and classification of diabetes mellitus. Provisional report of a WHO consultation. Diabet Med. 1998;15(7):539-53.

42. Lauritzen SL. Graphical models, vol. 17. London: Clarendon Press; 1996.

43. Villers F, Schaeffer B, Bertin C, Huet S. Assessing the validity domains of graphical Gaussian models in order to infer relationships among components of complex biological systems. Stat Appl Genet Mol Biol. 2008;7(2).

44. Højsgaard S, Edwards D, Lauritzen S. Graphical models with R: Springer Science \& Business Media; 2012.

45. Ahn Y-Y, Bagrow JP, Lehmann S. Link communities reveal multiscale complexity in networks. Nature. 2010;466(7307):761-4. 
46. Fereidani SS, Sedaghat F, Eini-Zinab H, Heidari Z, Jalali S, Mohammadi E, Naja F, Assadi M, Rashidkhani B. Gaussian Graphical Models Identified Food Intake Networks among Iranian Women with and without Breast Cancer: A Case-Control Study. Nutr Cancer. 2021;73(10):1890-7. https:// doi.org/10.1080/01635581.2020.1820051Epub 2020 Sep 14.

47. Krämer N, Schäfer J, Boulesteix A-L. Regularized estimation of large-scale gene association networks using graphical Gaussian models. BMC Bioinformatics. 2009;10(1):384.

48. Kalinka AT. The generation, visualization, and analysis of link communities in arbitrary networks with the R package linkcomm. Dresden: Max Planck Institute of Molecular Cell Biology and Genetics; 2014. p. 1-16.

49. Esmaillzadeh A, Kimiagar M, Mehrabi Y, Azadbakht L, Hu FB, Willett WC. Dietary patterns, insulin resistance, and prevalence of the metabolic syndrome in women. Am J Clin Nutr. 2007;85(3):910-8.

50. Paradis A-M, Godin G, Pérusse L, Vohl M-C. Associations between dietary patterns and obesity phenotypes. Int J Obes. 2009;33(12):1419-26.

51. Heidemann C, Scheidt-Nave C, Richter A, Mensink GB. Dietary patterns are associated with cardiometabolic risk factors in a representative study population of German adults. Br J Nutr. 2011;106(8):1253-62.

52. Aekplakorn W, Satheannoppakao W, Putwatana P, Taneepanichskul S, Kessomboon $\mathrm{P}$, Chongsuvivatwong $\mathrm{V}$, et al. Dietary pattern and metabolic syndrome in Thai adults. J Nutr Metab. 2015;2015.

53. Denova-Gutiérrez E, Castañón S, Talavera JO, Gallegos-Carrillo K, Flores M, Dosamantes-Carrasco D, et al. Dietary patterns are associated with metabolic syndrome in an urban Mexican population. J Nutr. 2010;140(10):1855-63.

54. Naja F, Nasreddine L, Itani L, Adra N, Sibai A, Hwalla N. Association between dietary patterns and the risk of metabolic syndrome among Lebanese adults. Eur J Nutr. 2013;52(1):97-105.

55. Amini M, Shafaeizadeh S, Zare M, Khosravi BH, Esmaillzadeh A. A crosssectional study on food patterns and adiposity among individuals with abnormal glucose homeostasis; 2012.

56. Min C, Noh H, Kang Y-S, Sim HJ, Baik HW, Song WO, et al. Breakfast patterns are associated with metabolic syndrome in Korean adults. Nutr Res Pract. 2012;6(1):61-7.

57. Suliga E, Kozieł D, Cieśla E, Głuszek S. Association between dietary patterns and metabolic syndrome in individuals with normal weight: a cross-sectional study. Nutr J. 2015;14(1):55.
58. Asghari G, Momenan M, Yuzbashian E, Mirmiran P, Azizi F. Dietary pattern and incidence of chronic kidney disease among adults: a populationbased study. Nutr Metab. 2018;15(1):88.

59. Johnston BC, Zeraatkar D, Han MA, Vernooij RW, Valli C, El Dib R, et al. Unprocessed red meat and processed meat consumption: dietary guideline recommendations from the nutritional recommendations (NutriRECS) consortium. Ann Intern Med. 2019;171(10):756-64.

60. Qian F, Riddle MC, Wylie-Rosett J, Hu FB. Red and processed meats and health risks: how strong is the evidence? Diabetes Care. 2020;43(2):265-71.

61. De Wit N, Derrien M, Bosch-Vermeulen H, Oosterink E, Keshtkar S, Duval C, et al. Saturated fat stimulates obesity and hepatic steatosis and affects gut microbiota composition by an enhanced overflow of dietary fat to the distal intestine. Am J Physiol Gastrointest Liver Physiol. 2012;303(5):G589-99.

62. Phillips CM, Kesse-Guyot E, McManus R, Hercberg S, Lairon D, Planells R, et al. High dietary saturated fat intake accentuates obesity risk associated with the fat mass and obesity-associated gene in adults. J Nutr. 2012;142(5):824-31.

63. DiNicolantonio JJ, O'Keefe JH. Good fats versus bad fats: a comparison of fatty acids in the promotion of insulin resistance, inflammation, and obesity. Mo Med. 2017;114(4):303.

64. Fats and fatty acids in human nutrition. Proceedings of the Joint FAO/ WHO Expert Consultation. November 10-14, 2008. Geneva, Switzerland. Ann Nutr Metab. 2009:55(1-3):5-300. https://doi.org/10.1159/000228993.

65. Mozaffarian D, Ludwig DS. The 2015 US dietary guidelines: lifting the ban on total dietary fat. JAMA. 2015:313(24):2421-2.

66. Kristal AR, Peters U, Potter JD. Is it time to abandon the food frequency questionnaire? Cancer Epidemiol Biomarkers Prev. 2005;14(12):2826-8. https://doi.org/10.1158/1055-9965.EPI-12-ED1.

\section{Publisher's Note}

Springer Nature remains neutral with regard to jurisdictional claims in published maps and institutional affiliations.
Ready to submit your research? Choose BMC and benefit from:

- fast, convenient online submission

- thorough peer review by experienced researchers in your field

- rapid publication on acceptance

- support for research data, including large and complex data types

- gold Open Access which fosters wider collaboration and increased citations

- maximum visibility for your research: over $100 \mathrm{M}$ website views per year

At BMC, research is always in progress.

Learn more biomedcentral.com/submissions 